\title{
An assessment of child immunization coverage and its determinants in Sinana District, Southeast Ethiopia
}

Elias Legesse* and Worku Dechasa

\begin{abstract}
Background: Immunization remains one of the most important public health interventions and cost effective strategies to reduce child mortality and morbidity associated with infectious diseases. It is estimated to avert between 2 and 3 million deaths each year worldwide. The objective of this study was to assess complete immunization coverage and its associated factors among children aged 12 to 23 months in Sinana district, Bale Zone, Southeast Ethiopia.
\end{abstract}

Methods: A cross-sectional community based survey was conducted in Sinana district from December 2012 to January 2013. A modified World Health Organization-Expanded Program on Immunization cluster sampling methods were used for household selection. A total 591 children aged 12 to 23 months and their mothers or caregivers were included in the study. Data were collected by using a pre-tested, interviewer administered questionnaire. Bivariate analysis was employed to identify factors associated with full immunization coverage and multiple logistic regression analysis was performed for those factors that showed statistically significant association in bivariate analysis and investigate independent predictors by controlling for possible confounders and significances of all tests were decided at p-value of 0.05 .

Results: More than three fourth (76.8\%) of the children aged 12 to 23 months were fully vaccinated by card plus history. Factors significantly associated with full immunization were antenatal care follow up (AOR $=3.7 ; 95 \% \mathrm{Cl}$ : 2.3 , 5.9), being a farmer ( $A O R=1.9 ; 95 \% \mathrm{Cl}: 1.1,3.1)$, being father with secondary and above educational level $(A O R=3.1$; $95 \%$ Cl: 1.3, 7.4), having household family income greater than 1000 ETB or 52 USD (AOR $=3.2 ; 95 \%$ Cl: 1.4, 7.4), those whose average walking time from home to health facilities is less than an hour ( $\mathrm{AOR}=3.1 ; 95 \% \mathrm{Cl}$ : 1.5, 6.3), those who had ever discussed about immunization with health extension workers ( $\mathrm{AOR}=2.4,95 \% \mathrm{Cl}: 1.3,4.2$ ) and mothers' with sufficient knowledge on immunization ( $\mathrm{AOR}=2.5 ; 95 \% \mathrm{Cl}: 1.5,4.2$ ).

Conclusions: Even though, immunization coverage of children in Sinana district gets improvement over national coverage, yet it is below governmental plan to increase the coverage i.e. 90\%. Maternal health care utilization and knowledge of mother about vaccine and vaccine preventable diseases are the main factors associated with complete immunization coverage. It is vital that local programmatic intervention should be strengthened to upgrade awareness of the community on the importance of immunization, antenatal care and working on advancing economic status of community is the way to optimize children's immunization coverage.

Keywords: Children, Immunization, Coverage, Vaccination, Determinants, Child mortality and morbidity

\footnotetext{
*Correspondence: siifankoo@gmail.com

College of Medical and Health Sciences, Department of Public Health,

Wollega University, Nekemte, Ethiopia
} 


\section{Background}

Universal immunization of children against six preventable diseases (tuberculosis, diphtheria, pertussis, tetanus, polio, and measles) is vital to reduce childhood mortality and morbidity across the world. So, it is one of the indicators of development in most developing countries. The Expanded Program on Immunization (EPI) was launched in 1974 as a global program for controlling and reducing death from Vaccine Preventable Diseases (VPDs). Thus, vaccine coverage is estimated as by convention with Diphtheria, Pertussis and Tetanus-3 (DPT-3) coverage achieved among children aged 12 to 23 months [1,2].

At the end of 2011, immunization was reported to have saved 2 to 3 million lives; nonetheless, in the same year 1.5 million children are estimated to have died (more than 70\% live in ten African and Asian countries) from VPDs is a reflection of the incomplete coverage with existing vaccines that persists in many parts of the world. Goal of Global Immunization Vision and Strategy (GIVS) was to reduce global measles deaths by $90 \%$ by the year 2010 or earlier $[3,4]$.

The WHO in Africa region and the Global Alliance for Vaccines and Immunization (GAVI) in 2000 have set a goal of reaching $\geq 80 \%$ DPT-3 coverage in every district in greater than $80 \%$ of developing countries by 2005 . This goal is referred as the " $80 / 80$ goal". To achieve this goal, the GAVI proposed a new approach, Reaching Every District (RED) in 2002 [4].

Millennium Development Goal 4 (MDG-4) aim is a two-thirds reduction of Under-Five Mortality Rate (U5MR) by 2015. Measles immunization coverage is one of the indicators for progress towards MDG-4. In 2008, there were an estimated 164,000 measles deaths globally. WHO estimated that during 2000 to 2007, measles caused deaths declined by $89 \%$ in Africa. However, measles outbreaks continue to occur throughout the region [5].

In 1980, the Government of Ethiopia (GoE) initiated the implementation of EPI with goal of increasing vaccination coverage against the six childhood killer diseases by $10 \%$ each year to reach $100 \%$ coverage in 1990. This program goal has largely remained unrealized even using different efforts [6].

Despite the high prevalence of VPDs in the country, immunization coverage rates stagnated and remained very low for many years. Health Sector Development Program IV (HSDP-IV) goal of the ministry of health EPI strategy is to achieve $96 \%$ DPT-3 coverage in all regions. The major hindering factors from achieving universal immunization include: low access to services, low number of trained manpower, high staff turnover, lack of fund donors, lack of information, lack of transportation, distance from health facilities, inadequate awareness of mothers/caregivers, others such as missed opportunities, and high dropout rates especially through routine approaches [7].

The Ethiopia Demographic Health Survey 2011 (EDHS-2011) showed coverage level for DPT-3 and the percentage of fully immunized children are reportedly $36.5 \%$ and $24.3 \%$ respectively. In Oromia region DPT-3 and full immunization coverage were $26.8 \%$ and $15.6 \%$ respectively. According to EDHS-2011, DPT-3 coverage in many of the regions was below $80 \%$, the lowest being in Afar region 9\%, the highest in Tigray $73.4 \%$ and in Oromia 26.8\% [8].

Infant Mortality Rate (IMR) stood at 59 per 1000 live births nationally, 73 per 1000 live births in Oromia region, and U5MR was 88 per 1000 live births for national and 112 per 1000 live births for Oromia region respectively. Reducing U5MR to $67 / 1000$ by 2015 can only be achieved if cost effective and high impacts interventions developed in support of the child health program are implemented at very high levels of coverage which includes among others: RED strategy, Integrated Management of Childhood Illness (IMCI) and Enhanced Outreach Strategy (EOS) [9]. In connection to this, pentavalent was introduced in 2006 with objective of increasing pentavalent three coverage to $88 \%$ by the end of 2011 [10,11].

In order to increase child immunization coverage, the underlying causes and parents' reasons not to immunize their children should be known. In the study area, so far no community based immunization coverage assessment study was conducted. Therefore, this study will try to fill these gaps by identifying the child immunization coverage and factors associated with full immunization. It will also help policy makers, program implementers and service providers to eliminate the obstacles and improve child immunization coverage in order to attain the intended prevention and control of VPDs. It also helps as a baseline for future studies.

\section{Methods}

\section{Study area and period}

The study was conducted in Sinana District, Bale zone, Oromia Region from December 2012 to January 2013. The district is located at a distance of 450 kilometers to southeast of Addis Ababa. Sinana district has 2 urban and 19 rural kebeles. According to the 2007 national census, the total population of Sinana district was 136,194 of which $66,735(48.99 \%)$ and $69,459(51.01 \%)$ were females and males respectively [12]; with 3,024(2.22\%) 12 to 23 month old children. There were 6 health centers, 20 health posts and 14 low level private clinics and 7 rural drug vendors in the district. But, EPI was all provided by governmental health centers and health posts. According to 2011/12 district health report, $85 \%$ of children were fully vaccinated [13]. 


\section{Study design}

A community based cross-sectional study design involving both quantitative and qualitative (focus group discussion and in-depth interview) approaches was employed.

\section{Source population}

All children aged 12 to 23 months with their mothers or caregivers living in Sinana district.

\section{Study population}

Randomly selected children aged 12 to 23 months with their mothers or caregivers living in Sinana district.

\section{Sample size}

\section{For quantitative data}

The sample size required for quantitative survey was computed using a formula of calculating single population proportions with the assumption of $5 \%$ margin of error, 95\% confidence level. Sample size was calculated by considering the estimated proportion of mothers knowledgeable on immunization (67.5\%) which was taken from recent study in Ethiopia [14]. Sample size was calculated for both specific objectives. The estimate which yielded the highest number was considered as a final sample size. After adjustment by using finite population correction formula and adding $10 \%$ non-response rate and by considering design effect of two, the final sample size was 606 children and their corresponding parents or caregivers.

\section{For qualitative data}

Totally, three Focus Group Discussions (FGDs) were conducted. In-depth interviews were conducted with health care providers of Primary Health Care (PHC) that included head of the selected health care provider working on immunization and Health Extension Workers (HEWs) from surrounding sub-sample of health facilities with 12 participants. Twelve reproductive age group mothers per FGD who had child 12 to 23 months of age were selected purposively from selected zones (those who are not participated in the quantitative study) during data collection. These were categorized in to three separate FGD sessions with consideration of homogeneity with respect to educational status, number of children and etc.

\section{Sampling technique}

Initially the total kebeles (21 kebeles in the district) were stratified into rural (19 kebeles) and urban (2 kebeles) areas. Then, five rural and one urban kebeles were selected by lottery method from the total kebeles in the district. Then, from each sampled kebeles, zones or subkebeles were selected by lottery method. The modified 2005 WHO-EPI cluster sampling method was employed to select study households with consideration of each zones/sub-kebeles as one cluster [15].

Then, the selection of the required number of children was from the selected households with proportional allocation of study subjects. The first child in each zone was selected randomly from the center of the zone and the rest of them were selected from the subsequent household till the required number of children have been attained. For households with more than one eligible child only one child was included by lottery method.

\section{Data collection}

It is an interviewer-administered structured questionnaire to obtain information from mothers or caregivers of the child by trained interviewers. The instrument was constructed from a review of available literature on immunization coverage, WHO questionnaire, and EDHS for immunization coverage and translated in to local language $[8,15,16]$.

The knowledge and attitude of the mothers or caregivers was assessed by six and five questions respectively. For data collection, the interviewers used a manual prepared by the investigators to help them understand the questionnaire to collect data. For qualitative parts, FGD guides were prepared by principal investigators.

Nine data collectors and three supervisors were recruited based on a set of criteria such as knowledge of the local language Afan Oromo and previous experience on data collection. They were trained for two days by the principal investigators on the purpose of the study, data collection tools or instruments, how to consent, how to select children from households, how to interview and how to extract information from immunization card and the overall data collection procedures.

Mothers or caregivers were asked to show immunization cards and the dates of immunization were extracted from the cards. For those whose immunization cards were not available or lost, the mothers or caregivers were asked on immunization status of their children. For instance, in the case of DPT and polio, the mothers or caregivers were asked to report the number of vaccines that the child has received. In order to reduce recall bias different recalling techniques such as routes of administration (checking injection sites and presence of the scar on the upper arm, whether the child has taken vaccine orally) were used.

\section{For qualitative data}

In-depth interviews were conducted with health professionals (probed on missed opportunities, health information delivery system and any difficulty or barriers to provide immunization service) and three FGDs were conducted with mothers or caregivers (probed on their knowledge, attitude towards immunization and barriers 
for not vaccinating their children). In-depth interviews were conducted by principal investigators. FGDs with mothers' or caregivers' were moderated by female diploma nurse. A single FGD lasts for an hour.

\section{Data analysis and quality management For quantitative data}

Data obtained from the questionnaire was entered, cleaned and prepared for tabulation using statistical data analysis software (Epi-Info version 3.5.3 and SPSS Version 20). Frequencies and other descriptive statistics were done. Bivariate analysis was conducted to examine association between dependent and independent variables; Odds Ratios (ORs) and their 95\% CIs were calculated. Then, all variables that has p-value less than 0.2 in the bivariate analysis were included in the multiple logistic regression analysis model to determine the factors associated with full immunization coverage among children aged 12 to 23 months old. Adjusted Odds Ratio (AOR) with their 95\% CIs were computed to determine the true association.

Data were categorized in to four groups (these groups were: socio-demographic characteristics, maternal health care use, child characteristics and mothers' knowledge of vaccine and vaccine preventable diseases) to see the association of explanatory variables with outcome variable. Then, from each of the group variables that had p-value of less than 0.05 were entered in to final model to control for confounders and to determine true association. Qualitative (FGDs and IDIs) data were transcribed, translated to English by replaying the tape recorder and analyzed by using thematic approach (by organizing the topics raised at the time of group discussion independently).

The questionnaire was pre-tested (on 5\% mothers or caregivers of children whose age was between 12 to 23 months) in kebeles which are not primarily selected for the study and the findings were excluded from main study. The necessary amendments were made upon identification of ambiguities of the tools in the wording, logic and skipping order. The principal investigators and the supervisors checked the collected data for completeness and $15(2.4 \%)$ questionnaires were rejected due to inconsistencies and incompleteness.

\section{Measurements}

Fully vaccinated: a child between 12 to 23 months who received one dose of Bacille Calmette Guerin (BCG), at least three doses of pentavalent, three doses of OPV and one dose of measles vaccine by card plus mother history.

Partially/incompletely immunized: a child 12 to 23 months who had missed one of the eight vaccines.

Not immunized: a child 12 to 23 months who didn't receive any vaccine before the study.
Coverage by card only: coverage calculated with numerator based only on documented dose, excluding from the numerator those vaccinated by history.

Coverage by card plus history: coverage calculated with numerator based on card and mother's report.

Missed opportunity: eligible child for vaccination had gone to health facility, but didn't receive vaccine for which he or she is eligible at that day.

Sufficient knowledge: six knowledge questions were asked and correct answers were given a score one and incorrect answers scored zero. Those scores which are greater than the mean were classified as having sufficient knowledge.

Positive attitude towards immunization: when the respondents positively reacted to at least three out of the four attitude questions regarding immunization.

Caregiver: is the most responsible person that provides child care for the 12 to 23 months old child whose biological mother couldn't provide the intimate care.

Index child: refers to 12 to 23 months child that is included randomly in the study from a household. In case, when more than one eligible child is present in a given household, one of them was selected at random to be included in the study.

Literate: mothers or caretakers or fathers with formal education or able to read and write.

Dropout rate (DOR): is the rate difference between the initial vaccines (BCG or Pentavalent I) and the final vaccines (Pentavalent III or Measles).

BCG to Measles dropout rate: the percent of children vaccinated for BCG who doesn't receive measles vaccine.

$$
\begin{aligned}
& \text { BCG/Measles dropout rate (over all dropout rate) } \\
& =\frac{(\text { BCG }- \text { Measles })}{\text { BCG }} * 100 \%
\end{aligned}
$$

Pentavalent I to pentavalent III dropout rate: the percent of children vaccinated for pentavalent I, but who did not receive pentavalent III.

$$
\begin{aligned}
& \text { Pentavalent I/Pentavalent III dropout rate } \\
& =\frac{(\text { Penta I - Penta III })}{\text { Penta I }} * 100 \%
\end{aligned}
$$

\section{Ethical considerations}

The research was approved by the research ethics review committee of the School of Public Health of Addis Ababa University before conducting the study. Permission to undertake the study was obtained from every relevant authorities in the zone, district and respective kebeles. Applicable consent form and the information sheet were duly integrated along with the respective data collection instruments. All the study participants were clearly informed about the objectives or purposes, 
procedures, risks and benefits, privacy and confidentiality issues of the study. Finally, verbal informed consent was obtained from each study participant before interview. This method of consent was specifically approved by the ethical committee that approved our study.

\section{Results}

\section{Socio-demographic characteristics of mothers or} caregivers

A total of 591 mothers or caregivers of children aged between 12 to 23 months were interviewed with a response rate of $98.5 \%$. Of the total 591 respondents, $562(95.1 \%)$ were mothers of the children and 29(4.9\%) were caregivers. Of the 591, 478(80.9\%) and $113(19.1 \%)$ of them were rural and urban residents respectively. The majority 575(97.3\%) of respondents belong to Oromo ethnic group, 313(53\%) of them Orthodox Christian followed by $265(44.8 \%)$ Islam in religion.

The median age of the mothers or caregivers was $28( \pm 6.1 \mathrm{SD})$ years, which ranges from 17 to 58 years. From the total respondents, 340(57.5\%) attended primary school, while 60(10.2\%) completed secondary school and above level and 191(32.3\%) of them can't read and write. In line to this, 309(52.3\%), 110(18.6\%) and 172(29.1\%) of the fathers (head of households) have attended primary school, secondary school or above and they have not gone to school for formal education respectively. More than half, 326(55.1\%) of mothers or caregivers and 528(89.3\%) of fathers were farmers. Almost three fourth of the families, 432(73.1\%) possess radio and only $141(23.9 \%)$ own television. Their mean monthly household income was 763.4 Ethiopian Birr (ETB) or 38 USD ( \pm 725.98 SD) and varying from 100 to $5000 \mathrm{ETB}$ or $\sim 5$ to 250 USD.

\section{Socio-demographic characteristics of children}

From a total of 591 children included in the study, 239(40.4\%) were females, 352(59.6\%) were males and $175(29.6 \%)$ of them aged exactly 23 months. The overall mean age of the children was $17.9( \pm 4.2$ SD) months. From the total children who have participated in this study, 576(97.5\%) were vaccinated at least once and $15(2.5 \%)$ were never vaccinated. Of those who have already vaccinated, $338(58.7 \%)$ and $218(37.8 \%)$ of them started the vaccine in age of $\leq 1$ month and between 2 and 3 months respectively. Parents showed vaccination card almost for one third, 195(33\%) of the children during the survey (refer Table 1).

\section{Availability and accessibility of vaccination services}

Almost all, 584(98.8\%) of respondents reported that they have access to health facilities that provide immunization services. Majority of them, 537(92.0\%) reported that they have more access to health post, 382(76.9\%) have access to services provided during outreach and $270(46.2 \%)$ have

Table 1 Socio-demographic characteristics of children aged 12 to 23 months in Sinana district, Bale zone, Oromia region, Southeast Ethiopia, 2012/13

\begin{tabular}{|c|c|c|c|}
\hline Variables & & Frequency & Percent (\%) \\
\hline \multicolumn{4}{|c|}{ Child's place of delivery } \\
\hline & Health facilities & 190 & 32.1 \\
\hline & Home & 401 & 67.9 \\
\hline \multicolumn{4}{|c|}{ Child's birth order } \\
\hline & First & 103 & 17.4 \\
\hline & Second & 125 & 21.2 \\
\hline & Third & 132 & 22.3 \\
\hline & Fourth & 82 & 13.9 \\
\hline & Fifth and above & 149 & 25.2 \\
\hline \multicolumn{4}{|c|}{ Child ever vaccinated } \\
\hline & Yes & 576 & 97.5 \\
\hline & No & 15 & 2.5 \\
\hline \multicolumn{4}{|c|}{ Age at which child started vaccination (in months) } \\
\hline & $\leq 1$ & 338 & 58.7 \\
\hline & 2 to 3 & 218 & 37.8 \\
\hline & 4 and above & 20 & 3.5 \\
\hline \multicolumn{4}{|c|}{ Children having vaccination card } \\
\hline & Yes & 190 & 33.0 \\
\hline & No & 386 & 67.0 \\
\hline
\end{tabular}


access to health center. As far as average distance to health facility in travel hours or minutes was concerned, $289(49.5 \%)$ of respondents have travelled $\leq 15$ minutes and 10(1.7\%) travelled greater than an hour (refer Table 2).

From the total, 573(97.9\%) of the households were visited by HEWs and 564(96.4\%) were given information on immunization by HEWs regularly. Of the total 576 mothers visited health facilities for vaccination, 119(20.7\%) turned back home without getting their children vaccinated. From this, the $69(58.0 \%)$ were due to the unavailability of the service providers and $62(52.1 \%)$ were due to lack of vaccine at these facilities.

\section{Knowledge and attitudes of mothers/caregivers on vaccination and VPDs}

Concerning knowledge of mothers on vaccination and VPDs; almost all, 573(97.0\%) have ever heard about vaccination. Majority of them, 548(95.6\%) heard about vaccination from HEWs and 526(91.8\%) heard from media (radio, television, newspapers etc.).

Almost all, 579(98.0\%) have replied that immunization prevents communicable diseases and 494(83.6\%) of them knew VPDs. As far as age at which children will receive BCG vaccine is concerned, 193(43.8\%) said at birth, $226(51.2 \%)$ at 2 weeks after birth and 21(4.8\%) at six weeks for BCG vaccine. Whereas for measles, $362(77.7 \%)$ reported at six months, $102(21.9 \%)$ at nine months and $2(0.4 \%)$ at twelve months. Out of the 518 who knew about when the child should complete the immunization, 509(98.3\%) reported the completion of immunization (i.e. before a year).

Study subjects were also asked for symptoms of VPDs and majority of them, $460(98.1 \%)$ reported rash of measles, $452(96.4 \%)$ cough and $446(95.1 \%)$ paralysis in case of polio. Overall more than two-third, $421(71.2 \%)$ of the study subjects were knowledgeable (have good

Table 2 Availability and accessibility of the vaccination services in Sinana district, Bale zone, Oromia region, Southeast Ethiopia, 2012/13

\begin{tabular}{|c|c|c|c|}
\hline Variables & & Frequency & Percent (\%) \\
\hline \multicolumn{4}{|l|}{ Presence of health facility } \\
\hline & Yes & 584 & 98.8 \\
\hline & No & 7 & 1.2 \\
\hline \multicolumn{4}{|l|}{ Number of health facility } \\
\hline & Health Center & 270 & 46.2 \\
\hline & Health Post & 537 & 92.0 \\
\hline \multicolumn{4}{|l|}{ Presence of outreach site } \\
\hline & Yes & 497 & 85.1 \\
\hline & No & 87 & 14.9 \\
\hline Number of active outreach site (in number) & & 382 & 76.9 \\
\hline \multicolumn{4}{|c|}{ Average distance to health facility in travel hours or minutes } \\
\hline & $\leq 15$ minutes & 289 & 49.5 \\
\hline & $>15$ minutes to $<30$ minutes & 173 & 29.6 \\
\hline & $\geq 30$ minutes to $\leq 1$ hour & 112 & 19.2 \\
\hline & $>1$ hour & 10 & 1.7 \\
\hline \multicolumn{4}{|l|}{ Convenience of services on vaccination } \\
\hline & Yes & 570 & 98.9 \\
\hline & No & 6 & 1.1 \\
\hline \multicolumn{4}{|l|}{ Presence of HEWs in the kebeles } \\
\hline & Yes & 585 & 99.0 \\
\hline & No & 6 & 1.0 \\
\hline \multicolumn{4}{|l|}{ HEWs visited your home } \\
\hline & Yes & 573 & 97.9 \\
\hline & No & 12 & 2.1 \\
\hline \multicolumn{4}{|l|}{ Given information on vaccination by HEWs } \\
\hline & Yes & 564 & 96.4 \\
\hline & No & 21 & 3.6 \\
\hline
\end{tabular}


knowledge and scored above the mean i.e. 4.95( $\pm 1.5 \mathrm{SD})$; whereas $170(28.8 \%)$ were completely non-knowledgeable (poor knowledge) regarding immunization. The summarized attitudinal index indicates that 587(99.3\%) of the total respondents have favorable attitude towards immunization services utilization; while the remaining $170(28.8 \%)$ have unfavorable attitude.

\section{Immunization coverage by card plus mother recall}

Based on the vaccination card and the mothers' recall, almost all 576(97.5\%) of the children took at least a single dose of vaccine. From the total vaccination report, $454(76.8 \%)$ were immunized completely (95\% CI: $73 \%$ to $80 \%$ ). Of the recommended vaccine doses in general, polio is the most frequently taken vaccine. Particularly OPV-1 was reportedly taken by $97.0 \%$ of the children followed by $95.9 \%$ of Penta-1, $93.6 \%$ of OPV-2, $93.2 \%$ of Penta-2 and $85.4 \%$ received OPV-3. Measles (77.7\%) was the least received vaccine.

More than three-fourth, (84.6\%) of the children have taken Penta-3 with $11.8 \%$ pentavalent dropout rate, $19.5 \%$ Penta- 1 to measles dropout rate and $15.8 \%$ overall dropout (BCG to measles) rates. The coverage of immunization showed decrement from the initial doses of vaccine to the last doses. Based on the information extracted from vaccination card, only 152(25.7\%) children completed all the recommended doses of vaccines.

\section{Factor affecting immunization completion for children}

In this study, factors associated with full immunization coverage were assessed. These factors include sociodemographic characteristics of mothers or caregivers and children, maternal health care utilization, availability and accessibility of health care services, knowledge of mothers or caregivers on vaccination and VPDs.

\section{Socio-demographic characteristics of mothers/caregivers}

Results from bivariate analysis indicated that maternal education, maternal occupation, father's education, family income and presence of radio or television in the house were the factors that were significantly associated with the increased completion of immunization among 12 to 23 months of children.

The presence of television and radio in their home also showed difference in completion of child immunization in multiple logistic regression. Children from the family who had television were 1.6 times more likely to complete their immunization than family who had no television $(\mathrm{AOR}=1.6 ; 95 \% \mathrm{CI}: 1.03,2.66)$. But, marital status, religion, ethnic group, occupation of father, family size and presence of radio in the house did not show an association on completion of child immunization in multiple logistic regression.
After adjusting for the other variables, only occupation of mother, educational level of father and family income remained significant in in multiple logistic regression. Concerning occupation, taking housewives as reference, children whose mothers are farmers were 1.9 times more likely to be fully vaccinated $(\mathrm{AOR}=1.9$; 95\% CI: 1.1, 3.1).

Children whose fathers have attended primary and secondary schools were 1.9 and 3.1 times more likely to be fully vaccinated than whose father unable to read and write $[(\mathrm{AOR}=1.8 ; 95 \% \mathrm{CI}: 1.02,3.11)$ and $(\mathrm{AOR}=3.1$; 95\% CI: 1.3, 7.4)] respectively. Concerning average monthly income of the family, children from the household with average monthly income $>1000$ ETB were 3.2 times more likely to complete their vaccination than children from the household with average monthly income of $<500$ ETB (AOR = 3.2; 95\% CI: 1.4, 7.4).

\section{Maternal health care utilization}

Antenatal care (ANC) follow up, post-natal care (PNC) follow up, whether mothers/caregivers ever visited health institutions and visited health facility specifically for immunization were assessed in bivariate analysis and all factors showed association with completion of child immunization (refer Table 3 for the descriptive and refer Table 4 for associated factors).

After adjusting for the other variables, only ANC utilization remained statistically significant in multivariate logistic regression. Mothers who have utilized ANC during the pregnancy of the index child were 3.7 [ $(95 \%$ CI: $2.3,5.9)]$ times more likely to fully immunize their children than mothers who have not utilized.

This finding is supported by the FGDs conducted with mothers. All discussants believed that visiting health facility during pregnancy and after delivery are very crucial for mothers and their children. The reasons forwarded were: if mother went to the health facility during pregnancy and post-delivery; health professionals would give advice and information on the progression of pregnancy, well-being of baby, alternative place of delivery and what to do after giving birth. Mothers could also be counselled on child immunization and how to feed the new born baby.

A 20 years old rural woman said that: "... when a mother took her child to health facility (to the health professionals), it is a good opportunity for getting advice and guidance on the initiation time of vaccines, when it should get completed and the importance of completing immunization for children. So, having ANC and PNC follow up is necessary for all mothers and their children..." 
Table 3 Maternal health care utilization in Sinana district, Bale zone, Oromia region, Southeast Ethiopia, 2012/13

\begin{tabular}{|c|c|c|c|}
\hline Variables & & Frequency & Percent (\%) \\
\hline \multicolumn{4}{|l|}{ ANC visit } \\
\hline & Yes & 435 & 73.6 \\
\hline & No & 156 & 26.4 \\
\hline \multicolumn{4}{|l|}{ PNC visit } \\
\hline & Yes & 305 & 51.6 \\
\hline & No & 286 & 48.4 \\
\hline \multicolumn{4}{|c|}{ Ever visit health facility for any purpose with child } \\
\hline & Yes & 572 & 96.8 \\
\hline & No & 19 & 3.2 \\
\hline \multicolumn{4}{|c|}{ Child received vaccines that day of visit } \\
\hline & Yes & 568 & 99.3 \\
\hline & No & 4 & 0.7 \\
\hline
\end{tabular}

\section{Availability and accessibility of health care services}

The association of health care availability and accessibility with the completion of vaccination were also seen by using bivariate and multivariate analysis (refer Table 5). Despite bivariate level significance, only average distance to the health facility in travel hours or minutes showed significant association in multivariate analysis, and mothers or caregivers who have travelled less than an hour were 3 times more likely to get their children fully vaccinated than mothers or caregivers travelled less than 15 minutes $(\mathrm{AOR}=3.1$; 95\% CI: 1.5, 6.3).

\section{Knowledge of mothers or caregivers on vaccination and VPDs}

Associations of mothers' knowledge about vaccination and VPDs with the completion of the Child immunization were third factor assessed (refer Table 6). After adjusting for the other variables, only two variables remained significant in multivariate logistic regression. Children whose mothers had good knowledge on vaccine and VPDs were 2.5 times more likely to be fully vaccinated than children of mothers who had poor knowledge on vaccine and VPDs $[$ AOR $=2.5 ; 95 \%$ CI: 1.5, 4.2)]. Similarly, mothers who ever have discussed on vaccination with HEWs were 2.4 times more likely to complete the immunization of their children than mothers who have not discussed on immunization with HEWs [(AOR = 2.4; 95\% CI: 1.3, 4.2)].

Findings of the FGDs also indicated that majority of mothers or caregivers remember immunization day during announcement for vaccination campaign. As discussants indicated, announcement at outreach site for vaccination of children is held each month on weekends.

Table 4 Completion of immunization among children aged 12 to 23 months by maternal health care utilization, Sinana district, Bale zone, Oromia region, Southeast Ethiopia, 2012/13

\begin{tabular}{|c|c|c|c|c|c|}
\hline \multirow[t]{2}{*}{ Variable } & & \multicolumn{2}{|c|}{ Fully vaccinated } & \multicolumn{2}{|c|}{ Odds ratio $(95 \% \mathrm{Cl})$} \\
\hline & & Yes & No & Crude & Adjusted \\
\hline \multicolumn{6}{|l|}{ ANC visit } \\
\hline & Yes & $359(60.7)$ & $76(12.9)$ & $3.0(2.0,4.6)^{*}$ & $3.7(2.3,5.9)^{*}$ \\
\hline & No & $95(16.1)$ & $61(10.3)$ & 1.00 & 1.00 \\
\hline \multicolumn{6}{|l|}{ PNC visit } \\
\hline & Yes & $250(42.3)$ & $55(9.3)$ & $1.8(1.2,2.7)^{*}$ & $1.0(0.6,1.8)$ \\
\hline & No & $204(34.5)$ & $82(13.9)$ & 1.00 & 1.00 \\
\hline \multicolumn{6}{|c|}{ Visit health facility for any purpose } \\
\hline & Yes & $452(76.5)$ & $120(20.3)$ & $32(7.3,140.5)^{*}$ & $\mathrm{Nl}$ \\
\hline & No & $2(0.3)$ & $17(2.9)$ & 1.00 & \\
\hline \multicolumn{6}{|c|}{ Child receive vaccine that day } \\
\hline & Yes & $450(78.4)$ & $120(20.9)$ & $3.8(0.5,26.9)$ & $1.8(0.1,21.7)$ \\
\hline & No & $2(0.3)$ & $2(0.3)$ & 1.00 & 1.00 \\
\hline
\end{tabular}

N.B: numbers in brackets are in percentage, $\mathrm{NI}$ - Variable not included in the model. *Significant at P-value of $<0.05$. 
Table 5 Completion of Child immunization among 12 to 23 months by availability and accessibility of health care service, Sinana district, Bale zone, Oromia region, Southeast Ethiopia, 2012/13

\begin{tabular}{|c|c|c|c|c|c|}
\hline \multirow[t]{2}{*}{ Variable } & & \multicolumn{2}{|c|}{ Fully vaccinated } & \multicolumn{2}{|c|}{ Odds ratio $(95 \% \mathrm{Cl})$} \\
\hline & & Yes & No & Crude & Adjusted \\
\hline \multicolumn{6}{|c|}{ Average distance to health facility in travel hours or minutes } \\
\hline & $\leq 15$ minutes & $210(35.5)$ & 79 (13.4) & 1.00 & \\
\hline & $>15$ minutes to $<30$ minutes & $136(23)$ & $37(6.3)$ & $1.4(0.9,2.2)$ & $1.6(0.9,2.6)$ \\
\hline & $\geq 30$ minutes to $\leq 1$ hour & $100(16.9)$ & $16(2.7)$ & $2.4(1.3,4.2)^{*}$ & $3.1(1.5,6.3)^{*}$ \\
\hline & $>1$ hour & $8(1.4)$ & $5(0.8)$ & $0.6(0.2,1.9)$ & $0.8(0.2,2.9)$ \\
\hline \multicolumn{6}{|c|}{ Service convenient } \\
\hline & Yes & $448(77.5)$ & $122(21.1)$ & $6.0(1.4,25.9)^{*}$ & $\mathrm{Nl}$ \\
\hline & No & $3(0.5)$ & $5(0.9)$ & 1.00 & \\
\hline \multicolumn{6}{|c|}{ Long waiting time at facility } \\
\hline & Yes & $420(73.7)$ & $117(20.5)$ & $0.6(0.2,1.7)$ & $1.7(0.6,4.6)$ \\
\hline & No & $28(4.9)$ & $5(0.9)$ & 1.00 & \\
\hline \multicolumn{6}{|c|}{ Turned back home without getting vaccine } \\
\hline & Yes & $91(15.4)$ & $28(4.7)$ & $0.9(0.6,1.6)$ & $0.8(0.5,1.3)$ \\
\hline & No & $363(61.4)$ & $109(18.5)$ & 1.00 & \\
\hline \multicolumn{6}{|c|}{ Presence of HEWs in kebeles } \\
\hline & Yes & $449(76)$ & $136(23)$ & $0.7(0.1,5.7)$ & $\mathrm{Nl}$ \\
\hline & No & $5(0.8)$ & $1(0.2)$ & 1.00 & \\
\hline \multicolumn{6}{|c|}{ HEWs given information } \\
\hline & Yes & $437(74.7)$ & $127(21.7)$ & $2.6(1.1,6.3)^{*}$ & $0.5(0.2,1.6)$ \\
\hline & No & $12(2.1)$ & $9(1.5)$ & 1.00 & \\
\hline
\end{tabular}

N.B: numbers in brackets are in percentage, NI- Variable not included in the model.

*Significant at P-value of $<0.05$.

Table 6 Completion of immunization among children aged 12 to 23 months by mothers or caregivers knowledge on vaccine and VPDs in Sinana district, Bale zone, Oromia region, Southeast Ethiopia, 2012/13

\begin{tabular}{|c|c|c|c|c|c|}
\hline \multirow[t]{2}{*}{ Variable } & & \multicolumn{2}{|c|}{ Fully vaccinated } & \multicolumn{2}{|c|}{ Odds ratio $(95 \% \mathrm{Cl})$} \\
\hline & & Yes & No & Crude & Adjusted \\
\hline \multicolumn{6}{|c|}{ Ever discussed on immunization with HEWs } \\
\hline & Yes & $372(62.9)$ & $74(12.5)$ & $3.9(2.6,5.8)^{*}$ & $2.4(1.3,4.2)^{*}$ \\
\hline & No & $82(13.9)$ & $63(10.7)$ & 1.00 & \\
\hline \multicolumn{6}{|c|}{ Ever encouraged to immunize last year } \\
\hline & Yes & $422(71.4)$ & $103(17.4)$ & $4.4(2.6,7.4)^{*}$ & $4.9(1.0,21.3)^{*}$ \\
\hline & No & $32(5.4)$ & $34(5.8)$ & 1.00 & \\
\hline \multicolumn{6}{|c|}{ Attitude of mothers/caretakers toward vaccination } \\
\hline & Negative attitude & $3(0.5)$ & $1(0.2)$ & 1.00 & \\
\hline & Positive attitude & $451(76.3)$ & $136(23)$ & $1.11(0.1,10.7)$ & $\mathrm{Nl}$ \\
\hline \multicolumn{6}{|c|}{ Knowledge of mothers/caretakers on vaccination } \\
\hline & Poor knowledge & $112(18.9)$ & $58(9.8)$ & 1.00 & \\
\hline & Good knowledge & $342(57.9)$ & 79 (13.4) & $2.2(1.5,3.4)$ & $2.5(1.5,4.2)^{*}$ \\
\hline
\end{tabular}

N.B: numbers in brackets are in percentage, NI- Variable not included in the model. *Significant at P-value of $<0.05$. 
So, this is convenient for mothers to get their children vaccinated.

A 34 years old uneducated mother from rural said that: "... I use outreach service to vaccinate my children. I remember the date from the announcement and since the outreach site is not too far, I'm vaccinating my children regularly by using such advantage. If other health problems happened on my children I took them to health facility, however in most of the cases for utilization immunization services, I use outreach site."

\section{Child characteristics}

The association of the child characteristics like sex, place of delivery and birth order with completion of child immunization were the variables assessed by this study. From these variables, only child birth order showed significant association with completion of immunization in both bivariate and multivariate logistic regression analysis. The likelihood of immunization completion among mothers with first birth order was less by $30 \%$ as compared with mothers with third birth order (AOR: 0.3; $95 \% \mathrm{CI}=0.2,0.4)($ refer Table 7$)$.

\section{Reasons for not being vaccinated among partially/} unvaccinated children

From the mothers/caregivers not immunized or not completed immunization for their children 85(62.0\%) responded due to lack of awareness on the necessity to return for second and third doses of vaccine, $47.4 \%$ reported place or time of immunization is not known and $14.6 \%$ of the mothers said that place of immunization is too far from home.

On the other hand, fear of adverse reaction (55.5\%), wrong ideas about contra-indications (48.2\%), lack of trust on immunization (38.7\%) and no confirmed information on immunization were reasons for not immunizing. In relation to this, FGDs indicated lack of awareness, fear of side effect, mothers give less attention to child immunization and males' involvement in child immunization is very low.

"... A friend of mine living in the rural has five children. She didn't gave birth at health facilities and none of her children were vaccinated because her husband didn't allow her to go health facilities for child immunization because she is burdened with many activities at home..." said by 25 years educated urban mother.

Other idea raised was fear of adverse reaction or side effects of the vaccinations which might discourage mothers not to go health facilities for the second visit.

Thirty years old rural woman said that: "... most of the children automatically develop fever and unusual discomfort for at least three days after getting vaccination which is really frustrating situation till they recovered even for families. I fear vaccination might decease my child. So, I never go again to vaccinate my child because I have seen the episode..."

Table 7 Immunization completion among children aged 12 to 23 months by child characteristics in Sinana district, Bale zone, Oromia, Southeast Ethiopia, 2012/13

\begin{tabular}{|c|c|c|c|c|c|}
\hline \multirow[t]{2}{*}{ Variable } & & \multicolumn{2}{|c|}{ Fully vaccinated } & \multicolumn{2}{|c|}{ Odds ratio $(95 \% \mathrm{Cl})$} \\
\hline & & Yes (\%) & No (\%) & Crude & Adjusted \\
\hline \multicolumn{6}{|c|}{ Sex of a child } \\
\hline & Female & $275(46.5)$ & $77(13.0)$ & 1.00 & \\
\hline & Male & $179(30.3)$ & $60(10.2)$ & $1.2(0.8,1.8)$ & $\mathrm{NI}$ \\
\hline \multicolumn{6}{|c|}{ Child place of delivery } \\
\hline & Home & $307(51.9)$ & $94(15.9)$ & 1.00 & \\
\hline & Health facility & $147(24.9)$ & $43(7.3)$ & $1.1(0.7,1.6)$ & $\mathrm{Nl}$ \\
\hline \multicolumn{6}{|c|}{ Child birth order } \\
\hline & First & $86(14.6)$ & $17(2.9)$ & 1.00 & \\
\hline & Second & $98(16.6)$ & $27(4.6)$ & $0.7(0.4,1.4)$ & $1.6(0.7,3.6)$ \\
\hline & Third & $95(16.1)$ & $37(6.3)$ & $0.5(0.3,0.9)^{*}$ & $0.3(0.2,0.4)^{*}$ \\
\hline & Fourth & $57(9.6)$ & $25(4.2)$ & $0.5(0.2,0.9)^{*}$ & $0.7(0.4,1.4)$ \\
\hline & Fifth & $118(19.9)$ & $31(5.2)$ & $0.8(0.4,1.5)$ & $0.6(0.3,1.2)$ \\
\hline
\end{tabular}


Table 8 Multivariate analysis for completion of child immunization (full immunization) and selected variables in Sinana district, Bale zone, Oromia region, Southeast Ethiopia, 2012/13

\begin{tabular}{|c|c|c|c|c|}
\hline \multirow[t]{2}{*}{ Variables } & \multicolumn{2}{|c|}{ Fully vaccinated } & \multicolumn{2}{|c|}{ Odds ratio $(95 \% \mathrm{Cl})$} \\
\hline & Yes & No & Crude & Adjusted \\
\hline \multicolumn{5}{|c|}{ Occupation of the mothers or caregivers } \\
\hline Housewife & 156 & 69 & 1.00 & 1.00 \\
\hline Farmer & 266 & 60 & $1.9(1.3,2.9)$ & $1.7(1.0,2.8)^{*}$ \\
\hline Others & 32 & 8 & $1.8(0.8,4.0)$ & $0.6(0.2,1.9)$ \\
\hline \multicolumn{5}{|l|}{ Educational level of father } \\
\hline Unable to read and write & 117 & 55 & 1.00 & 1.00 \\
\hline Primary level & 240 & 69 & $1.6(1.1,2.5)$ & $1.6(0.9,2.6)$ \\
\hline Secondary and above level & 97 & 13 & $3.5(1.8,6.8)$ & $2.8(1.3,6.2)^{*}$ \\
\hline \multicolumn{5}{|l|}{ Family income in ETB } \\
\hline 100 to 500 & 237 & 89 & 1.00 & 1.00 \\
\hline 501 to 1000 & 142 & 35 & $1.5(0.9,2.4)$ & $1.2(0.7,2.0)$ \\
\hline$>1000$ & 75 & 13 & $2.2(1.2,4.1)$ & $3.0(1.3,6.9)^{*}$ \\
\hline \multicolumn{5}{|l|}{ Visit ANC } \\
\hline Yes & 359 & 76 & $3.0(2.0,4.6)$ & $3.8(2.4,6.4)^{*}$ \\
\hline No & 95 & 61 & 1.00 & 1.00 \\
\hline \multicolumn{5}{|c|}{ Average distance to health facility in travel hours or minutes } \\
\hline$\leq 15$ minutes & 210 & 79 & 1.00 & 1.00 \\
\hline$>15$ minutes to $<30$ minutes & 136 & 37 & $1.4(0.9,2.2)$ & $1.5(0.9,2.5)$ \\
\hline$\geq 30$ minutes to $\leq 1$ hour & 100 & 16 & $2.4(1.3,4.2)$ & $3.0(1.5,6.1)^{*}$ \\
\hline$>1$ hour & 8 & 5 & $0.6(0.2,1.9)$ & $0.7(0.2,2.6)$ \\
\hline \multicolumn{5}{|c|}{ Ever discussed on immunization with HEWs } \\
\hline Yes & 372 & 74 & $3.9(2.6,5.8)$ & $2.1(1.2,3.9)^{*}$ \\
\hline No & 82 & 63 & 1.00 & 1.00 \\
\hline \multicolumn{5}{|c|}{ Knowledge of mother on immunization } \\
\hline Poor knowledge & 112 & 58 & 1.00 & 1.00 \\
\hline Good knowledge & 342 & 79 & $2.2(1.5,3.4)$ & $2.3(1.3,3.9)^{*}$ \\
\hline
\end{tabular}

*Significant at P-value of $<0.05$.

Health workers also indicated that negative attitude of the mothers or caregivers toward immunization; lack of trust on immunization are among the chief reasons that contributed a lot for low coverage of immunization in the district. Moreover, the mothers or caregivers didn't fully understood the benefits of vaccination rather they considered as it brought about fever and other discomforts to the children.

Thirty four years old mother stated that: “... mothers or caregivers lack awareness on benefits of vaccines. This might lead them to believe that vaccines cause diseases. Sometimes when observed practically after getting vaccination children will develop high fever and significant discomforts and then mothers or caregivers never return to the subsequent doses or appointment."
On the other hand, health workers agree that health information dissemination sessions which were given in mass do have problems. Mothers' or caregivers' level of understanding and educational background were not well recognized in particular. So, this could not motivate mothers for return.

“...on providing quality health information, we do have problems. It is not fully understood by our clients. It doesn't meet the expectations of the communities (specifically rural communities) in conveying the right kind information regarding immunization in casting out misconceptions. Yet, information we have provided, didn't bring the desired behavioral change...," said by 32 years old male health professional. 


\section{Discussion}

Immunization is one of the most successful and cost-effective public health interventions. Providing immunization service also offers an opportunity to deliver other preventive services, like vitamin A supplements and deworming. But, parents still do not perceive immunization as a right, and demand for immunization service is lacking or low in many developing countries. Antenatal care follow up, educational level of fathers, occupation of mothers and family income were some of the factors significantly associated with immunization coverage in this study. Despite the improvements, immunization is unfinished agenda in many developing countries including Ethiopia. So, this study tried to assess the full immunization coverage and factors associated with it among 12 to 23 months old children residing in Sinana district.

Oral polio vaccine coverage was slightly higher than the coverage of the pentavalent vaccine which is given in line with EPI schedule of Ethiopia. This is probably due to the OPV vaccine is given frequently as national campaign in the country. On the other hand, Penta-3 vaccine coverage was a bit higher than measles vaccine coverage which could be as a result of time gap between two vaccines in which mothers may forget the measles vaccine and dropout from the consequent doses.

Across all vaccine doses, from first to consequent doses, there is decrement of coverage which could be due to mothers or caregivers incompliance and time gap between each dose leading mothers to forget the subsequent doses. So, the dropout rate of Penta- 1 to Penta-3 was $11.8 \%$, Penta-1 to measles $19.5 \%$ and overall BCG to measles dropout was $15.8 \%$. The above figures are higher than the international goal set by WHO (i.e. making $<10 \%)$. But, this finding is less than the study done in Oromia region in which Penta- 1 to Penta-3 dropout rate was 33\% [17].

When we compare immunization coverage of Sinana district with that of Kafa [18], the Sinana coverage showed that $11.2 \%$ increment. This could be due to time gap between two studies and awareness of mothers on immunization could be changed over time. Availability and accessibility of the services might be other reason making these differences.

Similarly, when we compare immunization coverage of Sinana district with EDHS 2011, the percent of fully vaccinated is higher and proportion of children unvaccinated were decreased by $12.5 \%$. This is likely due to EDHS 2011 report included data from areas of low immunization coverage and time of the survey could also be another reason for the discrepancy. But, coverage of Penta-3, measles and fully immunized in Sinana district is lower than the immunization coverage reported in 2011 national and Oromia region health and health related indicators $[8,11]$. The percentage of fully vaccinated reported in this study $(76.8 \%)$ was also lower than the district health office report of 2011, which was $85 \%$. This is probably due to methods used, sample size, areas covered, over reporting and type of data sources used [13].

Among interviewed mothers, only 190(33\%) of the children immunization card was confirmed. Most of the children took OPV-1, followed by Penta-1. But, measles vaccine was the least utilized vaccine and $76.8 \%$ (95\% CI: $73 \%, 80 \%)$ of children completed the recommended doses of immunization.

Almost all, 97\% of mothers have heard about immunization. More than three fourth $(83.6 \%)$ of mothers knew VPDs. Majority of mothers heard on radio $(91.8 \%)$, which might indicate that mothers had access to medias. Kebeles in which village leaders participated in EPI program by giving information to habitants, motivating mothers and community on health service utilization also showed improvement in immunizing their children. This in turn might reveal the importance of political commitment to improve immunization status of children.

From this, more than half of the respondents knew at least more than six VPDs which are higher than study carried out in Ambo district in which majority of mothers knew more than three VPDs [14]. This difference might indicate that the information about immunization is made available for potential users in the study area.

In this study, mothers or caregivers educational status is among determinants of immunization completion and those mothers or caregivers who attended secondary and above level were two times more likely to complete the immunization of their children than mothers unable to read and write. This is may be as educational status of family gets improved, health seeking behavior of family may perhaps increase. This in turn may have positive impact on child immunization.

Other factor showed association with child immunization completion were fathers' educational level. This is consistent with finding from EDHS 2011, Istanbul, Northern Nigeria, Burkina Faso $[8,16,19,20]$. This could be due to household decision making power of father and awareness of father on vaccine and VPDs might make fathers at good position to vaccinate their children.

In this study, sex of child and place of delivery were not showed significant association with vaccine completion among 12 to 23 months old children. But, study from other places indicated that these factors have a significant association with child immunization status $[8,14,22]$. However, this study is consistent with survey in Mozambique in which gender has no difference in completing vaccination [23]. 
Mothers whose occupation is farmer were 1.7 times more likely to complete the immunization of child than housewives; the proportion of not fully vaccinated children are higher among housewives. This is similar with study in Jimma town, south west Ethiopia [24].

Family income is other factor included in multivariate; children from household whose average monthly income is greater than 1000 ETB were three times more likely to be fully vaccinated than whose income is low. If income of family is high, they will have access to medias, probably exposed to information through these media. This finding is consistent with study done in different areas $[8,20,25]$.

Maternal health care utilization was associated with child immunization completion among 12 to 23 months; children whose mothers had ANC follow up were more likely to be fully vaccinated than who did not attend ANC. This finding is consistent with that of India, Ambo, Mali, Nigeria [14,22,26,27]. This could be due to mothers health seeking behavior and mothers may discuss with health professionals on vaccine and VPDs, on importance of immunization, time of vaccine initiation, when it could get completed and possible side effect associated to vaccine during the follow up. So, it may create good opportunity for mother to get their children vaccinated. This could also motivate mothers to use health facility services.

Average walking time is other factor showed association with completion of child immunization. This finding is inconsistent with that of Philippines in which, as distance from health facility get more than $0.5 \mathrm{~km}$, the immunization coverage decreased. In addition to this, study from Mozambique showed that distance from health facility hinders immunization of children [23,28].

A 28 years old supervisor of HEWs in the district said that: "... the presence of HEWs working in community and outreach service which held on public holidays which mobilizes community to immunization monthly might played a significant role. So, this could help mothers to easily remember immunization day to vaccinate their children..."

A 35 years old mother from rural area said that: "... I'm using outreach services to get my child vaccinated by getting noticed through announcement and since distance of this outreach area is not too far I prefer to use this option. I'm vaccinating my child some times when my child gets sick at health post or health center."

Concerning knowledge of mothers on vaccine and VPDs; children whose mothers classified as having sufficient knowledge on immunization were twice more likely to be fully vaccinated than whose mother had little knowledge. This study is consistent with study done in Oromia region Ambo district, and Nouna district, Burkina Faso, Nigeria district, case control study in Wonago district south Ethiopia [20,21,24,29], as knowledge of mother improved on immunization, they could develop positive attitude. Then, they were motivated to complete the immunization.

Child birth order is associated to child immunization completion; and child born to the third and above birth order is $40 \%$ less likely to be fully vaccinated than first birth order. That means high proportion of children were found to be fully vaccinated among first birth order which is consistent to EDHS 2011 and study from Brazil $[8,21]$ finding in which child birth order related to vaccine completion. This could be child born to first birth order may get special focus since it has no resource competition and mothers may follow ANC for first child which may be related to health care utilization indeed.

The strength of this study is its inclusion of children aged 12 to 23 months which may measure recent immunization program performance and immunization completion rate. Information was triangulated by both quantitative and qualitative methods.

Immunization coverage by report of mother may under/over report the immunization coverage because mothers might not remember doses that child took due to recall bias. Being cross sectional study design which does not show the cause effect relationship is the other limitation of the study.

\section{Conclusions}

More than three fourth $(76.8 \%$ (95\%CI: 73\%, 80\%)) of children were fully vaccinated. Almost all (97\%) of mothers heard about immunization and $95.6 \%$ of the mothers heard from health extension workers. $98 \%$ of the mothers knew as immunization prevents communicable diseases and $71.2 \%$ of the mothers have sufficient knowledge on immunization. Among mothers participated in this study, $99.3 \%$ of them have positive attitude regarding vaccination. From the total children included in the study, only $33 \%$ of them have immunization card. Occupation of mothers/caretakers, household family income, educational level of father, sufficient knowledge, ever discuss about immunization, ANC follow up and average walking time were statistically significant predictors of fully immunization of children.

Being unaware of need for immunization, unaware of need to return for second or third dose, unknown place and/or time of immunization, fear of side effect, wrong ideas about contraindications, absence of faith in immunization, inconvenient time of immunization absence of vaccinator and vaccine and long waiting time at health facility were reasons for not fully immunizing their children. 


\section{Competing interests}

Authors declare that they have no competing interests.

\section{Authors' contributions}

WD has conceived of the study, carried out the overall design and execution of the study, design of questionnaires, performed the data collection, performed the statistical analysis and served as the lead author of the manuscript. EL participated in the drafting of the manuscript and assisted the design of the study and data analysis. All authors read and finally approved this manuscript for submission.

\section{Acknowledgements}

The authors would like to thank, United Nations Population Fund (UNFPA) for financial and technical support and Addis Ababa University for the all rounded support. We would like to acknowledge, Oromia Health Bureau and Sinana Health Office for their participation and facilitating the field work throughout the study period. Our appreciation also goes to the supervisors, data collectors and all of the district community especially mothers who generously and willingly participated in the study; without them this study would have been unthinkable.

\section{Received: 23 July 2014 Accepted: 10 March 2015}

Published online: 01 April 2015

\section{References}

1. Forder JA. Attitudes towards immunization in Cambodia: a qualitative study of health worker and community knowledge, attitudes and practices in Kampong Chhnang WHO. 2002.

2. WHO. Challenges in global immunization and the global immunization vision and strategy 2006-2015. Weekly Epidemiol Rec. 2006;81(9):189-96.

3. Ryman TK, Dietz V, Cairns KL. Too little but not too late: results of a literature review to improve routine immunization programs in developing countries. BMC Health Serv Res. 2008:8:134-48.

4. Federal ministry of health, WHO, UNICEF. Enhancing routine immunization services in Ethiopia: Reaching Every District (RED) approach, field guide and essential tools for implementation. Addis Ababa; 2004. 2004.

5. WHO. Children and the millennium development goals progress towards a world fit for children. Geneva; 2007

6. Berhane $Y$. Universal childhood immunization: a realistic yet not achieved goal. Ethiop J Health Dev. 2008;22(2):146-7.

7. Federal Ministry of Health. Expanded Program on Immunization (EPI). Addis Ababa; 2004

8. Central Statistical Agency (CSA), ORC Macro. Ethiopia Demographic and Health Survey 2011. Addis Ababa, Ethiopia and Calverton, Maryland: USACSA and ORC Macro; 2012.

9. Government of Ethiopia. Report on progress in implementing the world fit for children plan of action in Ethiopia. Addis Ababa; 2007

10. Federal ministry of health. Plan for the introduction of hepatitis $B$ and haemophilus influenza type $B$ vaccines into routine immunization in Ethiopia. Addis Ababa; 2005

11. Federal ministry of health. Health and Health related indicators. Addis Ababa; 2011

12. FDRE. Summary and statistical report of the 2007 population and housing census results. Addis Ababa; 2008

13. Sinana District Health Office. Compiled Sinana District Surveillance 2009/ 2010 (unpublished).

14. Etana B, Deressa W. Factors associated with complete immunization coverage in children aged 12-23 months in Ambo District. Central Ethiopia: BMC Public Health; 2012.

15. World Health Organization. Immunization coverage cluster survey reference manual. Immunization, Vaccines and Biologicals. Geneva: WHO/IVB/04.23; 2005.

16. Odusanya OO, Alufohai EF, Meurice FP, Ahonkhai VI. Determinants of vaccination coverage in rural Nigeria. BMC Public Health. 2008:8:381-8.

17. USAID. Essential services for health in Ethiopia and Oromia region, household survey. Addis Ababa; 2004

18. Shiferaw T. Survey of immunization levels and factors affecting program participation in Keffa, South-Western Ethiopia Ethiop. J Health Dev. 1990;4(1):55-74.

19. Torun SD, Bakirci N. Vaccination coverage and reasons for non-vaccination in a district of Istanbul. BMC Public Health. 2006;6:125-32.
20. Sanou A, Simboro S, Kouyaté B, Dugas M, Graham J, Bibeau G. Assessment of factors associated with complete immunization coverage in children aged 12-23 months. A cross-sectional study in Nouna district, Burkina Faso. BMC Int Health Human Rights. 2009;9 Suppl 1:10-23.

21. Barreto T, Rodrigues L. Factors influencing childhood immunization in an urban area of Brazil. J Epidemiol Community Health. 1992;46:357-61.

22. Saxena P, Prakesh D, Saxena V, Kansal S. Assessment of routine immunization in urban slum of Agra district. India Journal of Prev med. 2008;39(1):12-5

23. Mavimbe JC, Braa J, Bjune G. Assessing immunization data quality from routine reports in Mozambique. BMC Public Health. 2005;5:108-15.

24. Jira C. Reason for defaulting from expanded program of immunization in Jimma town south western Ethiopia. Ethiopia J Health Scie. 1999:9(2):93-9.

25. Tadesse H, Deribew A, Woldie M. Predictors of defaulting from completion of child immunization in South Ethiopia. BMC Public Health. 2009;9:150-6.

26. Koumaré AK, Traore D, Haidara F, Sissoko F, Traoré I, Dramé S, et al. Evaluation of immunization coverage within the expanded program on immunization in Kita Circle, Mali. A cross-sectional survey. BMC Int Health Human Rights. 2009;9 Suppl 1:13-9.

27. Babalola S, Lawan U. Factor's predicting BCG immunization status in northern Nigeria: a behavioral-ecological perspective. J Child Health Care. 2009;13:46-62

28. Friede AM, Waternaux C, Guyer B, de Jesus A, Filipp LC. An epidemiological assessment of immunization program participation in the Philippines. Int J Epidemiol. 1985;14(1):135-42.

29. $\mathrm{FMoH}, \mathrm{UNICEF}$. Guideline for enhanced outreach strategy for child survival initiation, revised Version March 2006, Addis Ababa.

\section{Submit your next manuscript to BioMed Central and take full advantage of:}

- Convenient online submission

- Thorough peer review

- No space constraints or color figure charges

- Immediate publication on acceptance

- Inclusion in PubMed, CAS, Scopus and Google Scholar

- Research which is freely available for redistribution 